\title{
Properties of Self Compacting Concrete at Different Curing Condition and their Comparison with properties of Normal Concrete
}

\author{
J. R. Al-Feel N. S. Al-Saffar \\ Civil Engineering Department, Mosul University
}

\begin{abstract}
The experimental investigation carried out is to study the effect of curing methods on the compressive, splitting, and flexural strengths (modulus of rupture) of self compacting concrete in comparison to those of normal concrete.

The self compacting concrete consisted of Portland cement (P.C) limestone powder (L.S) (L.S 8\% / 92\% P.C),sand, gravel and super-plasticizer. The specimens were cured in the air and water, for the period of 7, 14, and 28 days. Three specimens were tested for each point of each property. The results showed that the water cured specimens gave highest compressive strength, splitting tensile strength and flexural strength than specimens cured by air about 11\%, $10 \%$ and $11 \%$ for self compacting concrete at 28 days respectively.

The results also show that self compacting concrete gave high early strength i.e. strength before 28-days.

The failed specimens indicated that there was no segregation and a good bond between aggregate and matrix.
\end{abstract}

Keywords: Cement, limestone powder, Segregation, Self-Compaction.

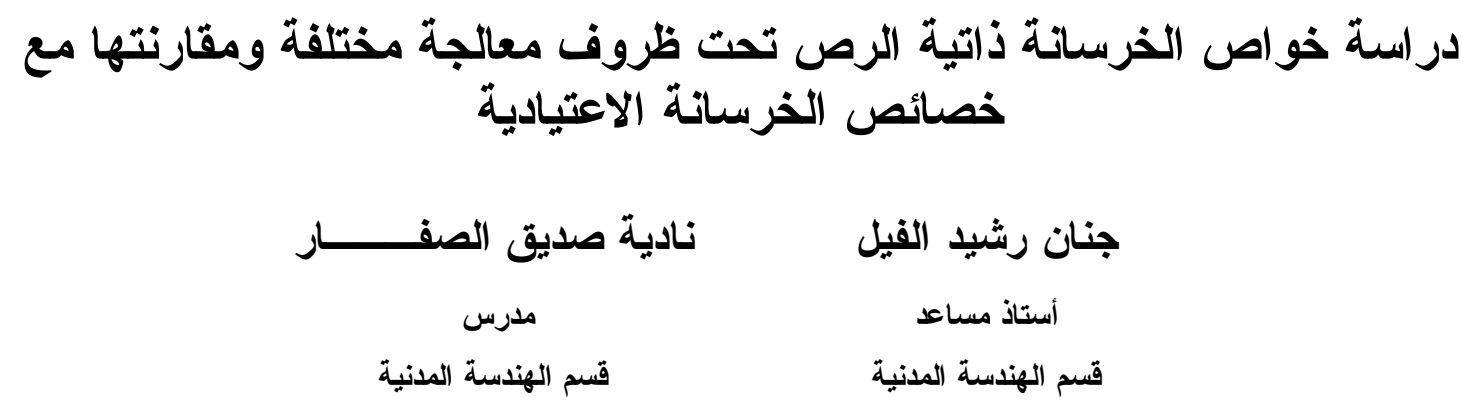

الخلاصة

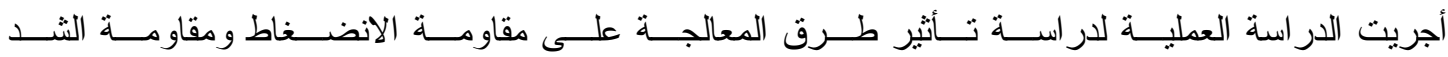

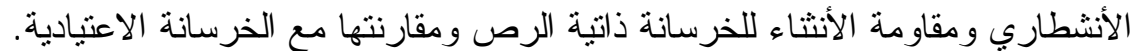

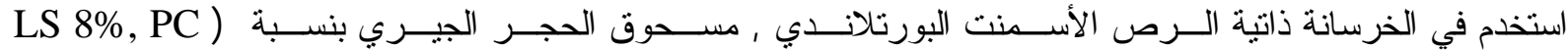

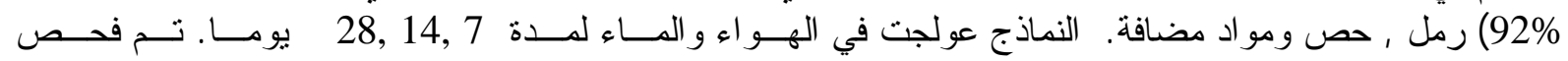
ثلاث نماذج لكل نقطة ولكل خاصية.

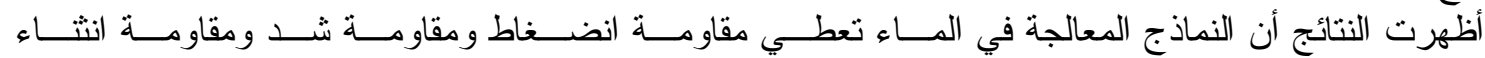

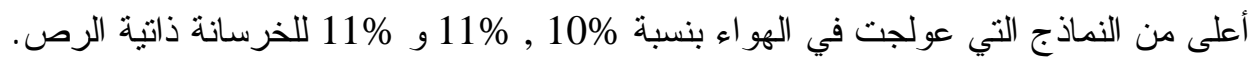

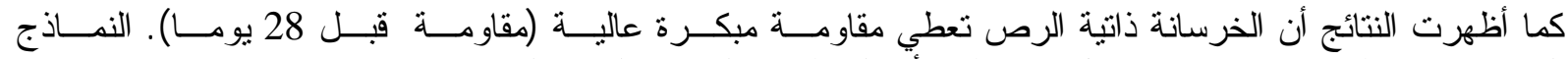
التي فحصت نظهر عدم وجود انفصال كما نظهر أن الربط بين الرئنة المونة و الركام الخشن جيد. 


\section{Al-Rafidain Engineering \\ Vol.17 No.3 \\ June 2009}

\section{Introduction:}

Self Compacting Concrete (SCC) was developed in the late 1980s in Japan [1]. Concrete is designed to flow under its own weight without mechanical compaction. SCC must be designed to resist segregation [1, 2]; SCC has high content of fine materials to provide stability of the mix resulting in resistance against bleeding and segregation. The fine materials such as fly ash, silica fume, granulated blast furnace slag, or limestone filler in SCC contributes significantly towards its fresh and hardened properties as well as reducing its cost [3]. It shows that scaling resistance of SCC depends on type of used admixture. Very good results are recorded with slag and also with limestone [4].

SCC usually contains super plasticizer to maintain the fluidity; SCC has many advantages such as, simple placement in complicated formwork and reinforcement, reducing construction times, reduced noise pollution, high and more homogenous concrete quality across the entire concrete cross section and improved concrete surfaces and finishes.

It is estimated that SCC may result in up to $40 \%$ faster construction than using normal concrete $[5,6]$. The elastic modulus and shrinkage of SCC did not differ significantly from the corresponding properties of normal concrete [7]. A simple mix design method for self-compacting concrete were proposed by $\mathrm{Su}$ [8] which is simpler, requires a smaller amount of binders, and saves cost

The curing conditions have significant effect on the degree of hydration of cement and there are significant differences between conventional vibrated concrete and SCC especially during curing, properties of SCC under various curing conditions need to be studied and its influence on some mechanical properties of SCC under different curing condition to be compared with normal vibrated concrete.

\section{Experimental Program:}

Portland cement from Badoosh factory was used for the preparation of all mixes and its chemical properties are shown in Table (1). Tap water was used for all mixes. River sand was used which is within the limitation of the B.S 1992 [9] its fineness modulus is 3.14. The maximum gravel size used was $(19 \mathrm{~mm})$, limestone powder passing sieve No. 200 was used at $8 \%$ of cement weight, Sikament - NN reducing concrete admixture used as super-plasticizer liquid, its color is dark brown and its density $1.2 \mathrm{~kg} / \mathrm{l}$. The dosage recommended by manufacture is $0.3-0.8 \%$ by weight of cement. The cement content of the mix used is $460 \mathrm{~kg} / \mathrm{m}^{3}$, the mix proportion used for normal vibrating concrete is 1:1.95:1.57:0.5 cement, sand, gravel, and W/C ratio respectively. The mix proportion used for SCC is shown in Table (2):

Table (1) Chemical Properties of Cement

\begin{tabular}{|c|c|c|}
\hline Constituent & Percentage & Specifications Limits \\
\hline \multicolumn{3}{|l|}{ 1-Oxide Composition } \\
\hline Alumina, $\mathrm{Al}_{2} \mathrm{O}_{3}$ & 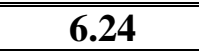 & 3.0-8.0 \\
\hline Silica, $\mathrm{SiO}_{2}$ & 21.39 & 17.0-25.0 \\
\hline Ferric Oxide, $\mathrm{Fe}_{2} \mathrm{O}_{3}$ & 2.64 & 0.5-6.0 \\
\hline Lime, $\mathrm{CaO}$ & 62.06 & 60.0-67.0 \\
\hline 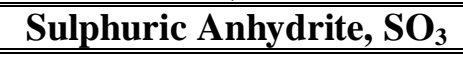 & 2.05 & Max. 2.8 \\
\hline Magnesia, MgO & 2.7 & Max.5 \\
\hline \multicolumn{3}{|l|}{ 2-Compound Composition } \\
\hline$\overline{\mathrm{C}_{3} \mathrm{~A}}$ & 12.07 & 11.96-12.30 \\
\hline $\mathrm{C}_{2} \mathrm{~S}$ & 37.70 & 28.61-37.90 \\
\hline $\mathrm{C}_{3} \mathrm{~S}$ & 31.49 & 31.30-41.05 \\
\hline$\overline{\mathrm{C}_{4} \mathrm{AF}}$ & $\overline{8.01}$ & 7.72-8.02 \\
\hline
\end{tabular}


Table (2) Mix Proportion for SCC.

\begin{tabular}{|c|c|c|c||c|}
\hline Cement & Sand & Gravel & Lime & Water/Binder W/B \\
\hline \hline 1 & 2.11 & 1.7 & $8 \%$ of Cement & 0.33 \\
\hline
\end{tabular}

W/B is water to binder (Cement +Lime) ratio. The dry materials were mixed in a horizontal pan mixer. The admixture was dissolved in the mixing water and added to the mix then mixed for two minute to get a good homogeneous mix. The slump-flow test was used which consists of one slump cone and one flow table. A concentric diameter of $500 \mathrm{~mm}$ is marked on the table. The slump cone is filled with concrete while pressing the slump cone to the table, next the slump cone is lifted vertically and the time measurement is started. Time for the concrete diameter to reach 500 $\mathrm{mm}\left(\mathrm{T}_{50}\right)$ is recoded and the final diameter when the concrete stopped flowing is recorded (D final). The mix was homogeneous and stable as shown in Fig.(1).

The time recorded for $500 \mathrm{~mm}$ diameter of concrete was $4 \mathrm{sec}$ and the final concrete diameter about $600 \mathrm{~mm}$.

A (100 ) mm cube molds were used for the compressive strength test, and (200x100) $\mathrm{mm}$ cylinder for splitting test and $(100 \times 100 \times 500) \mathrm{mm}$ prisms used for flexural test. The concrete was poured into the molds without compaction. After 24 hours of casting, some of the specimens were immersed in water and others were left in the air until they were tested (at the age of 7,14 , and 28 days)

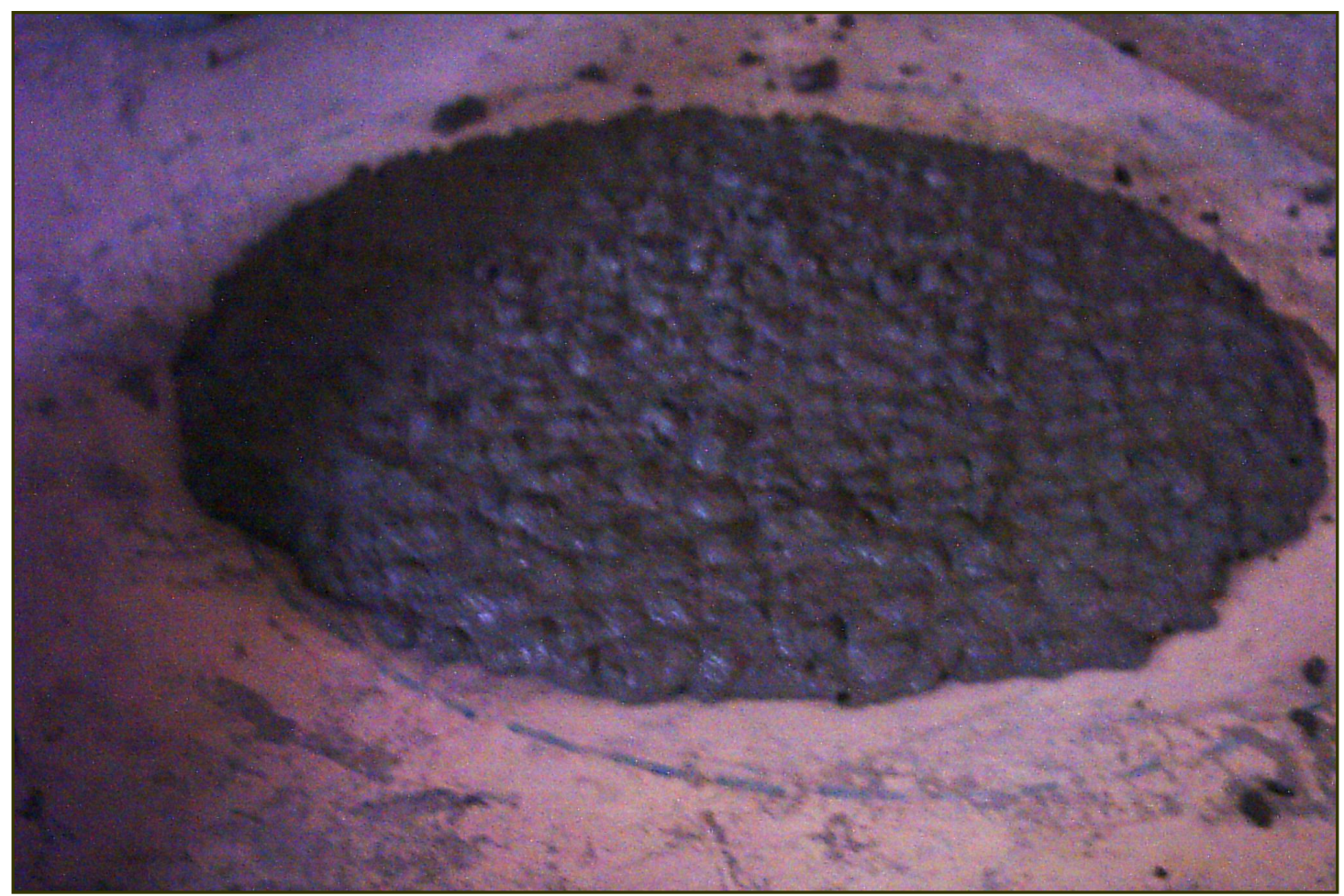

Fig. (1) Flow Test of SCC concrete. 


\section{Results and Discussion}

\section{Concrete Density:}

Density of normal and self compacting concrete was determined by weighing the cube specimens, before testing. The final densities for each type of concrete have been calculated by averaging the densities of three specimens. Results are presented in Table (3), the results show that normal and self-compacting concretes have the same density for water cured specimens, but slightly different for air cured specimens.

Table (3) Density for Normal and Self Compacting Concrete.

\begin{tabular}{|c||c||c|}
\hline & Water Curing & Air-Curing \\
\hline Normal concrete $\mathrm{kg} / \mathrm{m}^{3}$ & 2488 & 2378 \\
\hline Self Compacting Concrete $\mathrm{kg} / \mathrm{m}^{3}$ & 2483 & 2425 \\
\hline
\end{tabular}

\section{Compressive Strength:}

The cube compressive strength test results of SCC for cubes cured in water and air are shown in Fig. (2). each point is the average of three results. It can be seen from this figure that the compressive strength of specimens cured in water is higher than that for those cured in air for the entire curing duration (about 11\%). The results indicated that the SCC gave high early strength (before 28 days) values compared to normal concrete as shown in Fig.(3) and it seems that the SCC gave higher compressive strength than normal concrete for the entire curing duration regardless of the curing condition, see Fig.(4). The strength gain at 7 days was about $90 \%$ percentage of 28-days strength for SCC and $80 \%$ for normal concrete, while it was $96 \%$ for SCC at the age of 14 days,

This indicates that the additional admixture contributed to improvement of compressive strength regardless of curing condition and time. The SCC provided higher compressive strength of $30 \%$ at 28 days as compared to that of normal concrete cured in water and this value increased for specimens cured in air; this indicates that the mixing water for SCC is relatively in excess of that required for full hydration of cement.

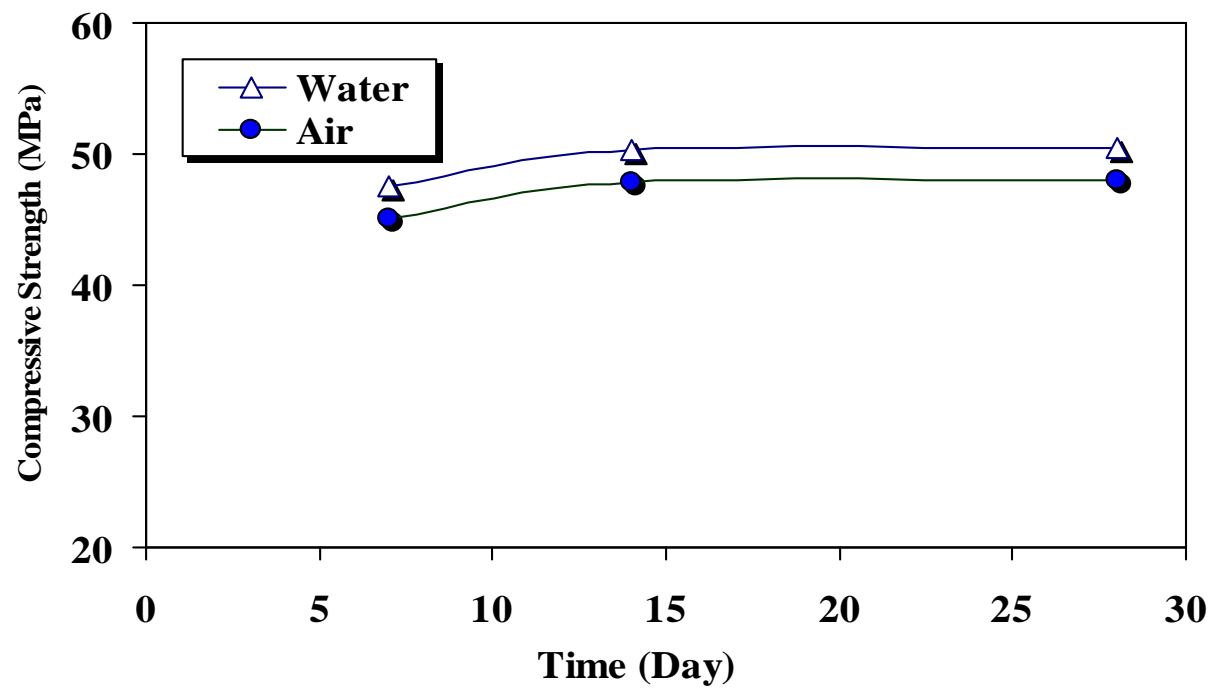

Fig.(2) Variation of Compressive Strength with Time for Different Curing conditions 


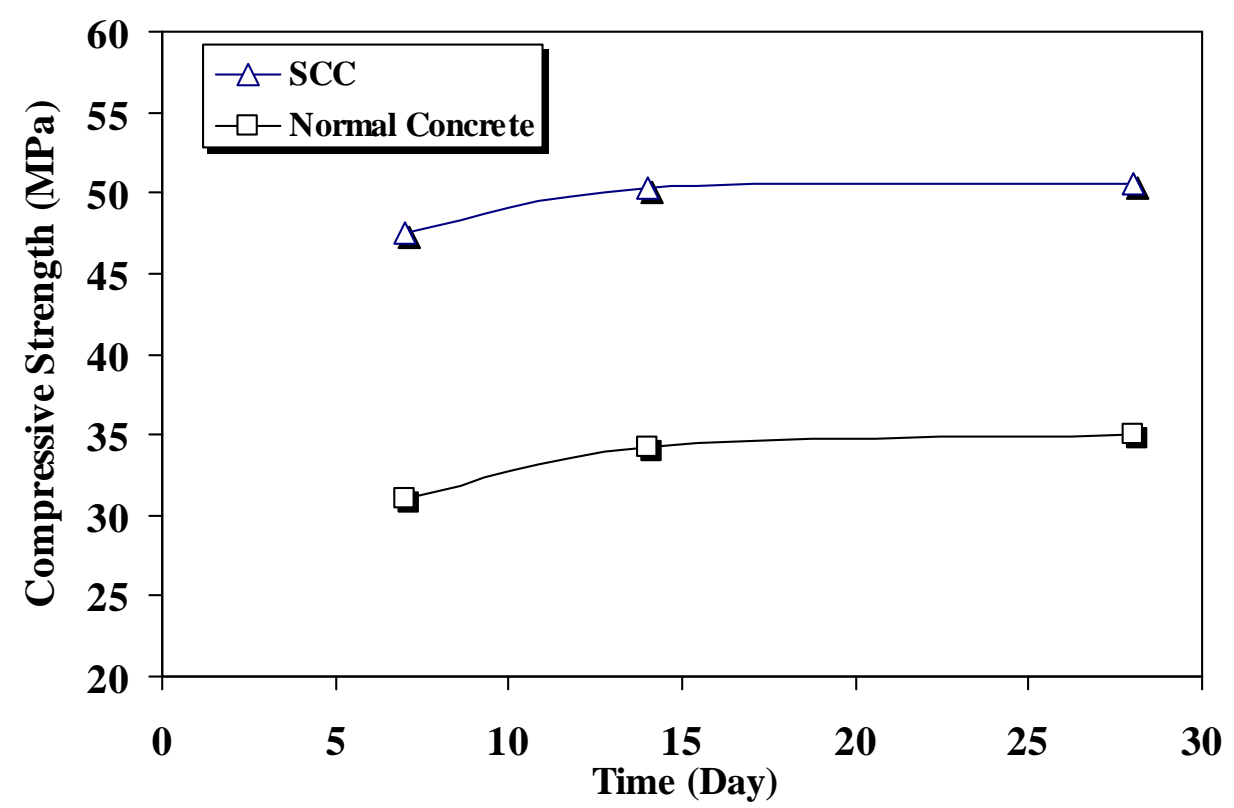

Fig.(3) Variation of Compressive Strength with Time for SCC and Normal Concrete Cured in Water.

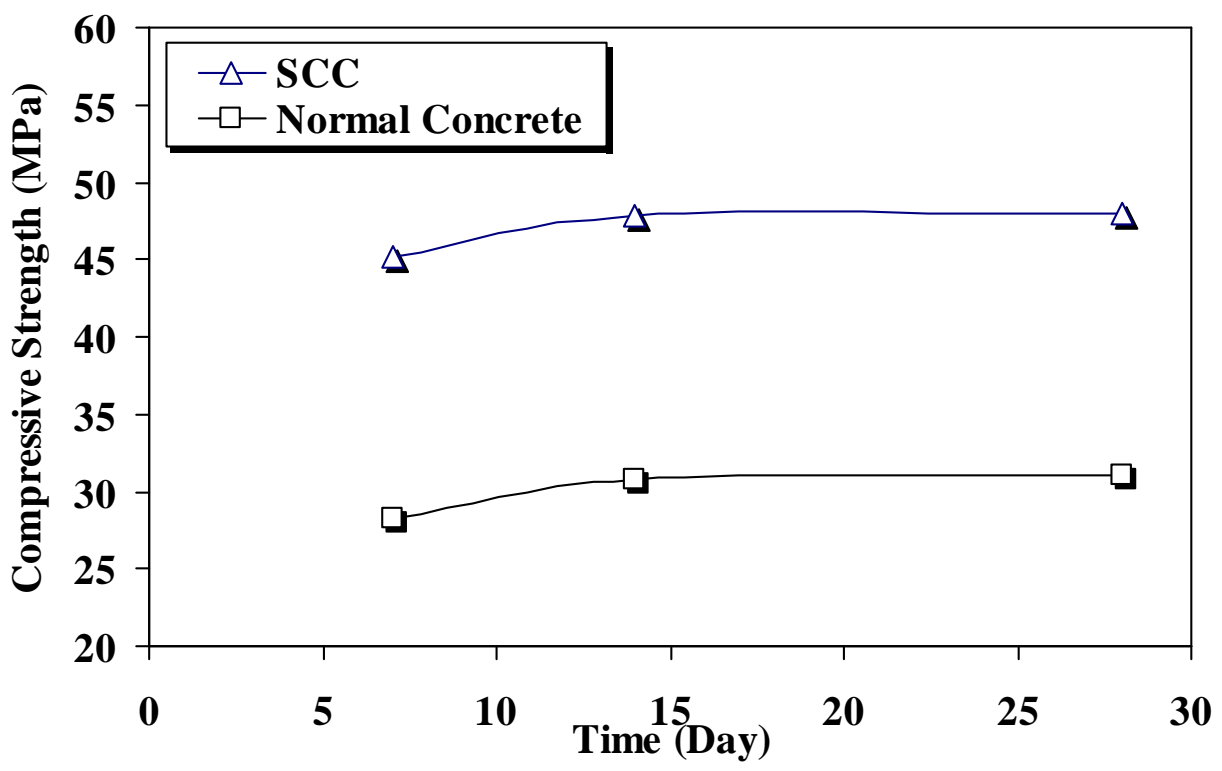

Fig.(4) Variation of Compressive Strength with Time for SCC and Normal Concrete Cured in Air 


\section{Al-Rafidain Engineering \\ Vol.17 No.3 \\ June 2009}

\section{Tensile Strength (Splitting tension):}

Fig. (5) shows the tensile splitting strength results for specimens cured in air and water for 7,14 , and 28 days.

This figure indicated that the development of tensile strength of SCC cured in water is higher than air cured specimens. A comparison between the tensile strength with that of normal concrete is given in Figs. $(6,7)$ for specimens cured in water and air respectively.

The figures show that for the SCC the tensile strength is higher than that for normal concrete for all periods of curing regardless of curing method. This contributed significantly to the admixture addition.

The splitting tensile strength for SCC cured in water or air at 28 days is increased by $25 \%$ compared to that of normal concrete, This indicates that the type of curing is not so important for the development of tensile strength of SCC.

A comparison of tensile and compressive strength indicates that the compressive strength is more sensitive to the curing method than the tensile strength.

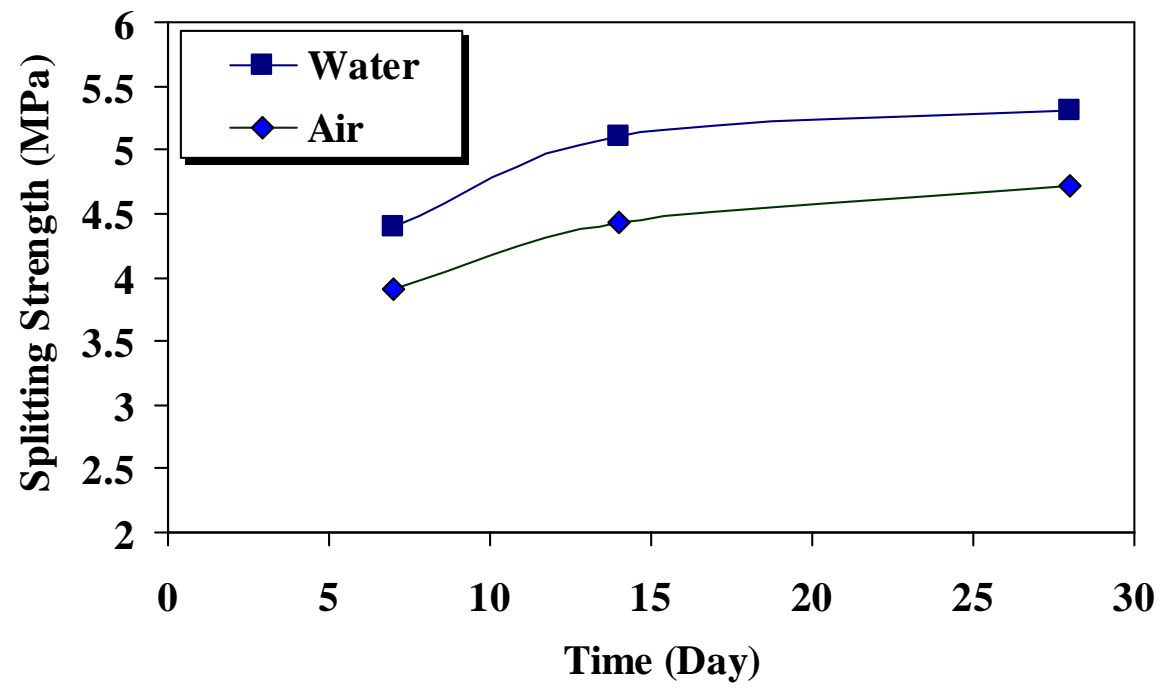

Fig.(5) Variation of Splitting Strength with Time in Different Curing Condition for SCC.

\section{Flexural Strength (Modulus of Rupture):}

The $(100 \times 100 \times 500) \mathrm{mm}$ were tested at third point on a span of $400 \mathrm{~mm}$ are shown in Table (3) for both SCC and normal concrete at 28 days for different curing conditions.

Table (3) Results of Flexural Strength.

\begin{tabular}{|l|c|c||}
\hline Flexural Strength at 28 days (MPa) & Cured in Water & Cured in Air \\
\hline \hline SCC & 4.41 & 3.91 \\
\hline \hline Normal Concrete & 3.00 & 2.55 \\
\hline
\end{tabular}




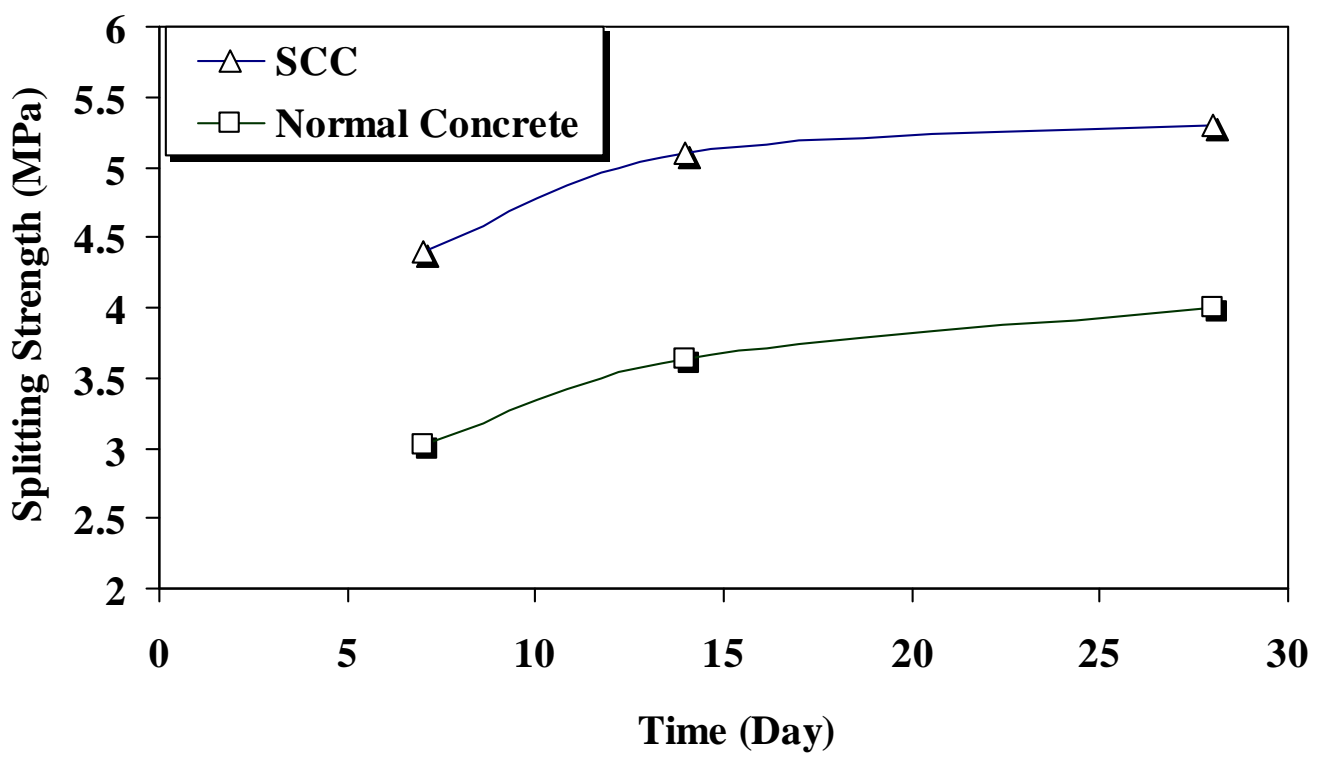

Fig.(6) Variation of Splitting Strength for SCC and Normal Concrete with Time Cured in Water.

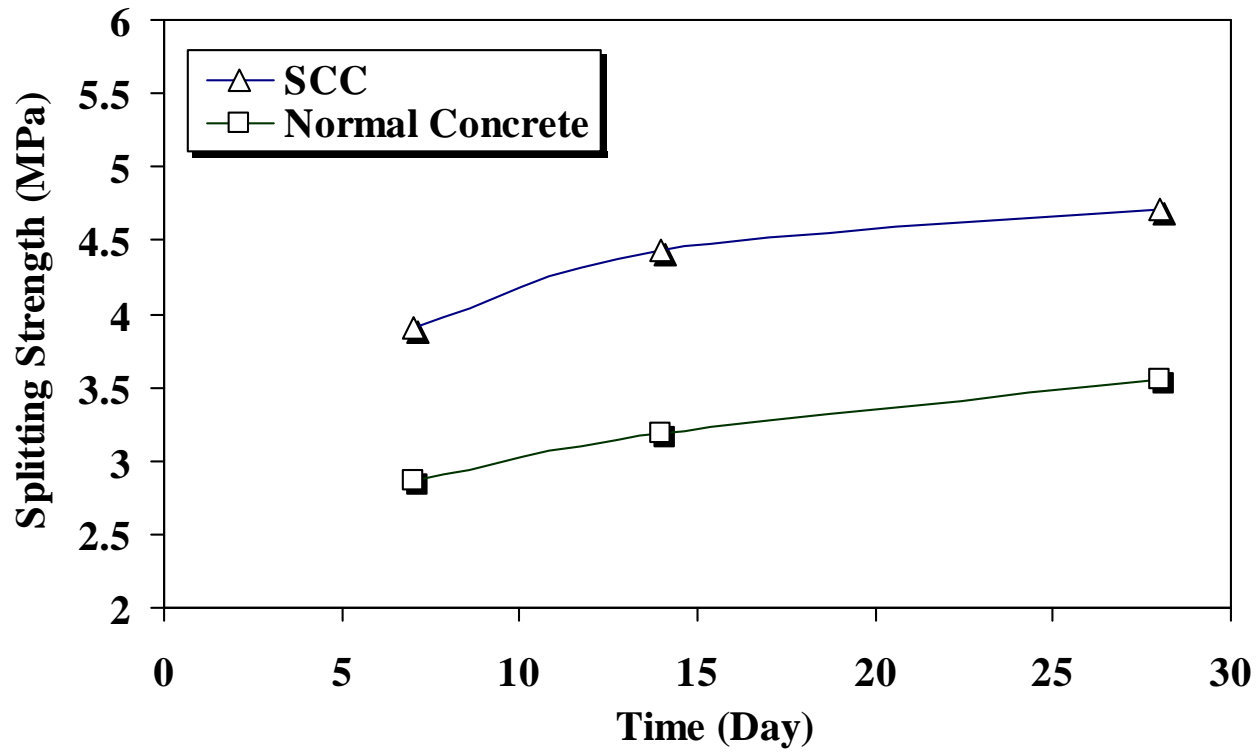

Fig.(7) Variation of Splitting Strength for SCC and Normal Concrete with Time Cured in Air.

The results show that the specimens for SCC and normal cured in water gave higher flexural strength than those specimens cured in air; each value is the result of three specimens.

But the results indicate that curing condition of SCC and normal concrete is not so effective on the results. The flexural strength for specimen cured in water is $11 \%$ more than specimens cured in air for SCC. 


\begin{tabular}{llll} 
Al-Rafidain Engineering & Vol.17 & No.3 & June 2009 \\
\hline
\end{tabular}

\section{Modes of Failure}

Fig.(8) shows the failure mode for the tested specimens of SCC, the figure shows that the aggregate is equally distributed at the cross section, this indicates that no segregation occurred, Fig.(8.A) and the figure shows that failure occurred sometimes in the aggregate or in the matrix Fig.(8.B) this indicates a good bond between the matrix and aggregate. The failure mode for flexural specimens show cracks formation nearly at mid-span Fig.(8.C), this indicates a homogenous mix and good bond.

(A)
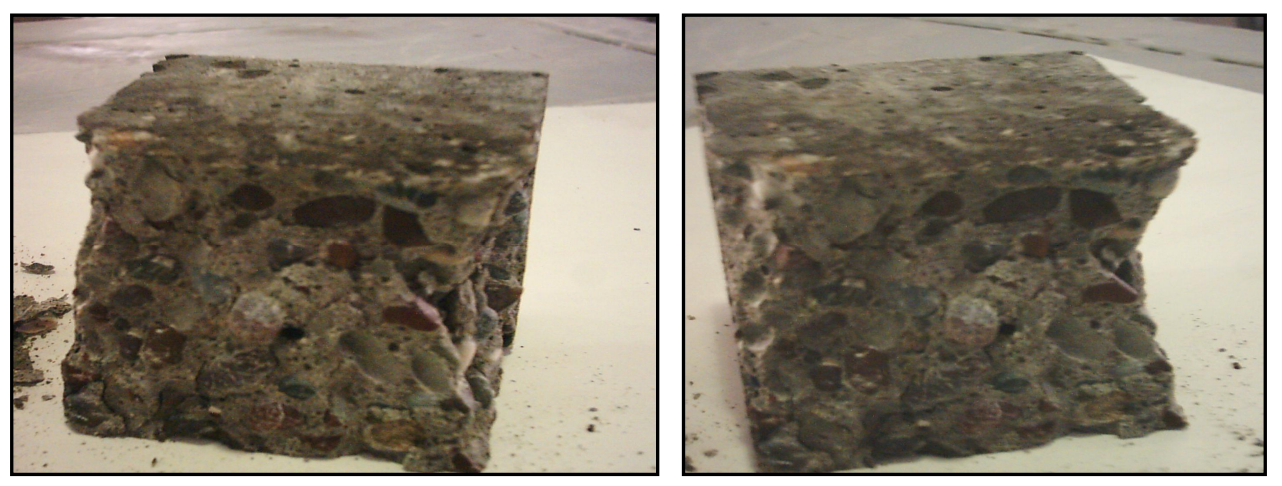

(B)
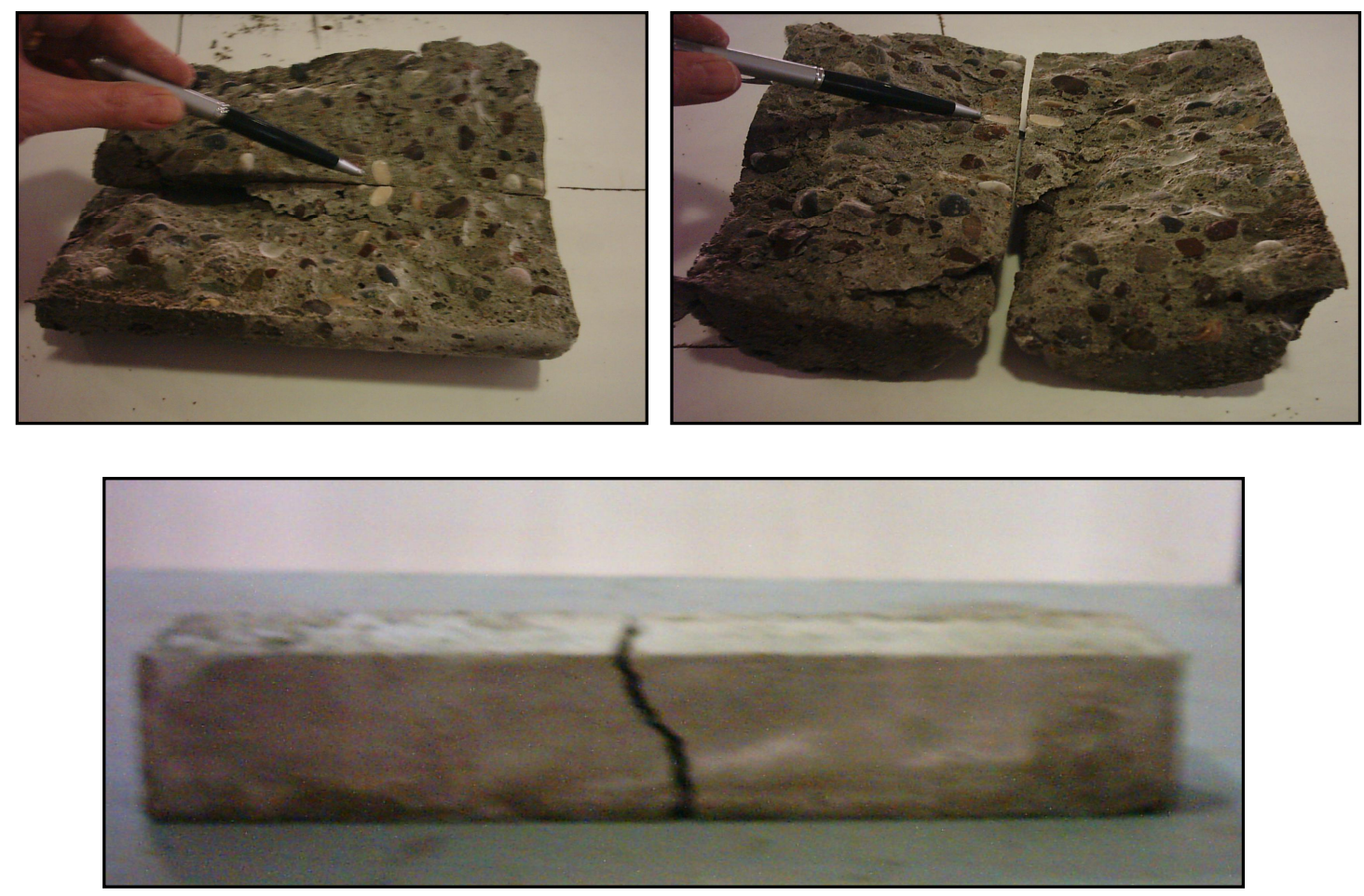

(C)

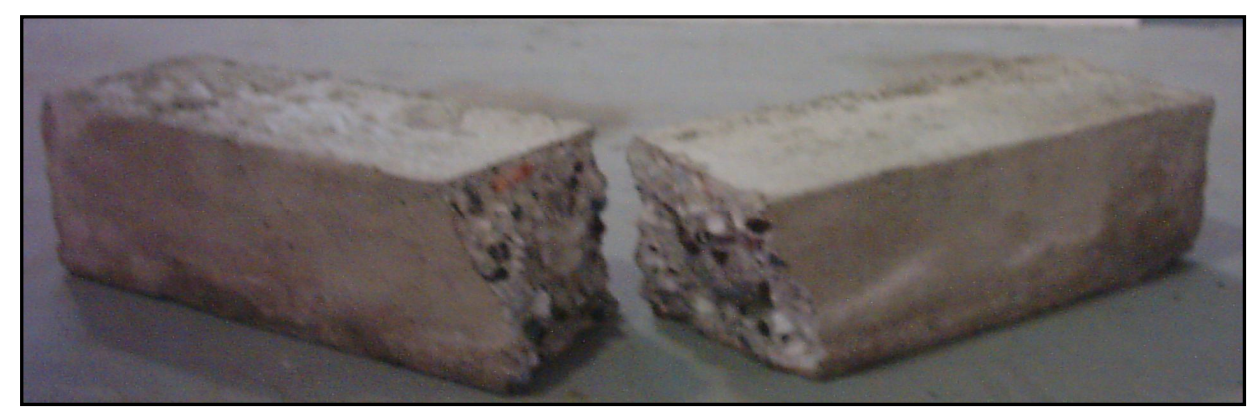

Fig.(8) Modes of Failure for Test Specimens. 


\section{Al-Feel: Properties of Self Compacting Concrete at Different Curing Condition and}

\section{Conclusions}

From the experimental investigation carried out, the following conclusions can be drawn:

1- The compressive and tensile strength of Self-Compacting Concrete were higher than those of ordinary concrete at all considered ages and for all curing condition. The SCC gave high early strength (before 28-days).

2- The water cured specimens gave slightly highest compressive strength values than those specimens cured by air for SCC, this indicate that curing condition not so effective .

3- The failure specimens showed that there was no segregation in the mix constituents and good bond between aggregate and matrix.

\section{References}

1. Ozama K, MackawaA K, Konishima M, and Okamura H, "Performance of concrete based on the durability design of concrete structures", proceeding of the second East Asia-pacific Conference on Structural Engineering and Construction, Chiang Mai, Thailand, 1989.

2. Shindoh T, Yokota K, and Yokoi K, "Effect of mix constituent on rheological properties of super workable concrete, proceeding of the international RILEM Conference, Production Methods and Workability of concrete, Paisley, Scotland, 1996.

3. Yahia A, Tamawara M, Shimabukuro A, and Shimoyama Y," Effect of Rheological Parameters on Self Compatibility of Concrete Containing Varies Mineral Admixture, proceeding of the first RILEM. International symposium on self compacting concrete, Stockholm, 1999.

4. Bilek V, Sehmid P, "Properties of self compacting concrete with different fine admixtures and their comparison with properties of usual concrete, proceeding of the International Conference held at the University of Dundee, Scotland, UK on July 2005, pp 251-260.

5. Perssoiv B, Technical Report, Japan Society for the promotion of Science, Report 9803:12, Division of Building Materials, Lund Institute of Technology, Lund , 1998.

6. Nocher M, Flowing Smoothly and Quietly, Advanced Concrete and Masonry Center, Concrete Quarterly, Issue 198, spring 2001, UK.

7. Bertil Persson, A Comparison between Mechanical Properties of SelfCompacting Concrete and the Corresponding Properties of Normal Concrete, Cement and Concrete Research, 2001,pp.193-198.

8. Su, N., Hsu, K .C. and Chai, H.W. A Simple Mix Design Method for SelfCompacting Concrete, Cement and Concrete Research, 2001, pp.1799-1807.

9. British Standard Institution, B.S 882, 1992. "Aggregates from natural sources for concrete". 